\title{
USO DO TERRITÓRIO NO RIO GRANDE DO NORTE, CÍRCULOS DE COOPERAÇÃO E A REDE XIQUE-XIQUE DE ECONOMIA SOLIDÁRIA
}

\author{
Felipe Silveira Felix ${ }^{1}$ \\ Celso Donizete Locatel ${ }^{2}$
}

\section{Resumo}

A Economia Solidária envolve diversas formas de organização pautadas na autogestão e na cooperação e, a entendemos enquanto uma alternativa para os (as) trabalhadores (as) que buscam nela as condições para conseguirem uma nova perspectiva de trabalho e de renda. As lógicas cooperativas e solidárias, nesse sentido, inserem-se de maneira diferente no território, modificando seu uso. Nessa perspectiva, combinam-se os usos e acirram-se as disputas, de um lado, os agentes hegemônicos, de outro, os Empreendimentos Econômicos Solidários que buscam, através de ações de resistência, reproduzir-se frente as adversidades encontradas. Dessa forma, buscamos compreender o uso do território a partir das ações em rede da Rede Xique-Xique o ambiente institucional da Economia Solidária no Rio Grande do Norte e analisar o Círculo de Cooperação contra-hegemônico constituído a partir das práticas solidárias.

Palavras-Chaves: Uso do território, economia solidária, círculos de cooperação, Rio Grande do Norte.

\section{THE USE OF TERRITORY IN RIO GRANDE DO NORTE, COOPERATION CIRCLES AND THE XIQUE-XIQUE NETWORK OF SOLIDARITY ECONOMY}

\begin{abstract}
The Solidarity Economy involves autogestionary and cooperative enterprises organizations. We understand it as an alternative for all the workers who see in solidary logic, a way to bring another work and income perspective. Thus, these solidary logics promote a different way to experience and use the territory. Land uses change and recombine; disputes among all parties intensify. Hegemonic agents confront these solidary economy enterprises that seek, through resistance actions, to extend themselves in the face of all the adversities experienced. Therefore, this paper finds to understand the use of territory from the network actions of the Xique-Xique Network, the institutional environment of solidarity economy in Rio Grande do Norte state and analysis the constitution of a counter-hegemonic circle of cooperation by solidary practices.
\end{abstract}

Keywords: Use of territory, solidarity economy, cooperation circles, Rio Grande do Norte.

\footnotetext{
${ }^{1}$ Mestrando em Geografia no Programa de Pós-Graduação e Pesquisa em Geografia da Universidade Federal do Rio Grande do Norte (PPGe/UFRN). E-mail: felipe.silveira.099@ufrn.edu.br

${ }^{2}$ Professor Associado da Universidade Federal do Rio Grande do Norte e docente do Programa de Pós-

Graduação e Pesquisa em Geografia (PPGe/UFRN). E-mail: celso.locatel@ gmail.com
} 


\section{USO DEL TERRITORIO EN RIO GRANDE DO NORTE, CÍRCULOS DE COOPERACIÓN Y RED DE ECONOMÍA SOLIDARIA XIQUE- XIQUE}

\section{Resumen}

La Economía Solidaria envuelve varias formas de organización basadas en la autogestión y en la cooperación. La entendemos como una alternativa para los trabajadores que buscan en ella las condiciones para obtener una nueva perspectiva de trabajo y renta. Las lógicas cooperativas y solidarias, en este sentido, se insertan de manera diferente en el territorio, modificando su uso. En esta perspectiva, se combinan los usos y se intensifican las disputas, por un lado, los agentes hegemónicos, por otro, las Empresas de Economía Solidaria que buscan, a través de acciones de resistencia, reproducirse ante las adversidades encontradas. Así, buscamos comprender el uso del territorio a partir de las acciones en red de la Red Xique-Xique, el entorno institucional de la Economía Solidaria en Rio Grande do Norte y analizar el Círculo de Cooperación contrahegemónico constituido a partir de prácticas solidarias.

Palabras clave: Uso del territorio, economía solidaria, círculo de cooperación, Rio Grande do Norte.

\section{INTRODUÇÃO}

Num período cada vez mais intenso, no qual as relações se dão de forma acelerada, com a competitividade sendo parte do modus operandi global, a economia solidária surge enquanto alternativa contra-hegemônica a uma lógica de dominação e de subjugação dos(as) trabalhadores(as). As ações globalizantes dos grandes agentes incidem verticalmente no território, desregulando e modificando antigas solidariedades orgânicas e intensificando antigas desigualdades.

Neste período, denominado técnico-científico-informacional por Santos (2006), grandes corporações e outros agentes de maior poder adquirem cada vez mais força e poder de decisão. O território passa, cada vez mais, a ser tutelado, não apenas pelo Estado, mas também por esses outros agentes hegemônicos. Há, nesse sentido, um redimensionamento no papel do Estado, o qual, embora conflite com as lógicas das grandes corporações, ainda assim dá as garantias para a reprodução ampliada do capital, uma vez que também se alia a tais lógicas.

A economia solidária, diante dessa realidade, surge como alternativa para os(as) trabalhadores(as) subjugados e sujeitados aos processos de dominação e de ampliação do capital, os quais buscam novas formas de emancipação e também uma nova realidade econômica, social e de trabalho. Por essa razão, associam-se ou criam empreendimentos solidários a fim de mitigarem tais problemas. 
Nesse sentido, no Brasil, a economia solidária apresenta-se na condição de alternativa com potencial força de modificação no que se refere às mudanças sociais, econômicas e de trabalho, já que busca, a partir do confronto com o modelo hegemônico, atenuar e mitigar as desigualdades. Realmente há problemas com a operacionalização da Política Pública em Economia Solidária no país, uma vez que dá pouca capacidade de emancipação e de autonomia aos(às) trabalhadores(as), visto os parcos recursos destinados às políticas de desenvolvimento social.

Levando isso em consideração, objetiva-se, com este trabalho, entender como se dá o uso do território a partir das ações da Rede Xique-Xique de Comercialização Solidária, bem como o círculo de cooperação contra-hegemônico que se constitui a partir da atuação da Rede. Para isso, discutiremos em 3 sessões alguns importantes temas, a saber: as características da Economia Solidária no Brasil e no Rio Grande do Norte na segunda sessão; a Economia Solidária, os círculos de cooperação hegemônicos e contra-hegemônicos e o uso do território na terceira sessão; e, por fim, a Rede Xique-Xique, discutindo seus princípios e sua materialidade no estado do $\mathrm{RN}$.

\section{CARACTERÍSTICAS DA ECONOMIA SOLIDÁRIA NO BRASIL E NO RIO GRANDE DO NORTE}

A Economia Solidária, no Brasil, caracteriza-se de maneira diversa, estando ligada ao Estado, a partir da regulamentação e da política pública de economia solidária, executada entre 2003 e 2015, e aos movimentos sociais, tidos como alternativa de organização dos(as) trabalhadores(as) sumidos ao contexto de exclusão presente no modelo hegemônico.

Realizada de maneira solidária e coletiva pelos(as) trabalhadores(as), a economia solidária envolve diversas etapas de desenvolvimento, integrando produção, distribuição, circulação, consumo, poupança e crédito (de maneira cooperativa e autogestionária). Surge em contextos de articulação entre grupos que se organizam em forma de cooperativas, de associações ou de redes de cooperação, alternativa viável à sua reprodução (AZEVEDO; SILVA; ALIÓ, 2014).

Há uma grande diversidade de agentes envolvidos no surgimento da economia solidária, bem como em sua institucionalização. Dentre os grupos e organizações, destacam-se a Associação Nacional de Empresas de Autogestão (ANTEAG), a Agência de Desenvolvimento Solidário (ADS/CUT), a União e Solidariedade das Cooperativas e Empreendimentos de Economia Social do Brasil (UNISOL), além de organismos católicos, como a Cáritas e a 
Comissão Pastoral da Terra (CPT). De acordo com Pires e Rossi (2017), além das Cáritas, existem outros grupos e instituições de origem católica ligados ao surgimento da economia solidária no país, como é o caso da Federação de Órgãos para a Assistência Social e Educacional (FASE), do Instituto Brasileiro de Análises Sociais e Econômicas (IBASE) e também do Instituto de Políticas Alternativas do Cone Sul.

O que percebemos é que esses diversos agentes envolvidos possibilitaram e tiveram atuação importante no que se refere à criação do Fórum Brasileiro de Economia Solidária (PIRES; ROSSI, 2017). Isso demonstra a forte relação entre a economia solidária e os movimentos sociais, haja vista que buscavam fortalecer a ação dos(as) trabalhadores(as) que buscavam na autogestão uma alternativa de enfrentamento das desigualdades vivenciadas.

A Economia Solidária, institucionalizada enquanto política pública, foi operacionalizada pelo Estado e acabou por ganhar um viés que a distanciou de suas bases teóricas e horizontais. De acordo com Forbeloni (2011), ela surge através de iniciativas populares, justamente na ausência de ações e de políticas públicas por parte do Estado.

Nesse sentido, a Economia Solidária institucionaliza-se no Brasil no ano de 2003, durante o governo de Luís Inácio Lula da Silva (2003-2011), em nível federal, a partir de um marco regulatório que congrega um conjunto de normas, leis e diretrizes, sendo as principais a Lei $n^{\circ} 10.683$ e do Decreto $n^{\circ} 4.764$, que criou a Secretaria Nacional de Economia Solidária (SENAES), a qual está inserida no Ministério do Trabalho e Emprego (MTE), como observam Silva e Nagem (2011).

Além da criação da SENAES, Lima (2015) afirma que a implementação do Programa Economia Solidária em Desenvolvimento (PESD) deu-se na tentativa de promoção e de fortalecimento dos Empreendimentos Econômicos Solidários (EES) do país, visando ao bom desenvolvimento e à inclusão social dos(as) trabalhadores(as) aos EES.

A partir dos dados do último mapeamento realizado pelo Sistema Nacional de Informações em Economia Solidária (SIES), em 2013, estavam mapeados, no país, 19.708 EES, distribuídos nas cinco macrorregiões. Estes estavam organizados em forma de: Associação (60\%), Grupo Informal (30,5\%), Cooperativa (8,8\%) e Sociedade Mercantil (0,6\%), conforme SIES (2013).

No Mapa 1, pode-se observar a distribuição espacial dos EES no território nacional, bem como a forma de organização por estado da federação. Observa-se, no mapa, que há uma predominância de associações e de grupo informais, o que se explica pela menor burocratização 
para sua criação e formalização. Por outro lado, de acordo com os dados do SIES (2013), as cooperativas concentram-se na região Sul, com cerca de $18 \%$ dos empreendimentos em relação ao total de 3.292 presentes na região. Além disso, a região Nordeste concentra a grande maioria dos EES do país $(40,80 \%)$.

Mapa 1. Brasil: Quantidade de EES e as formas de organização (2013)

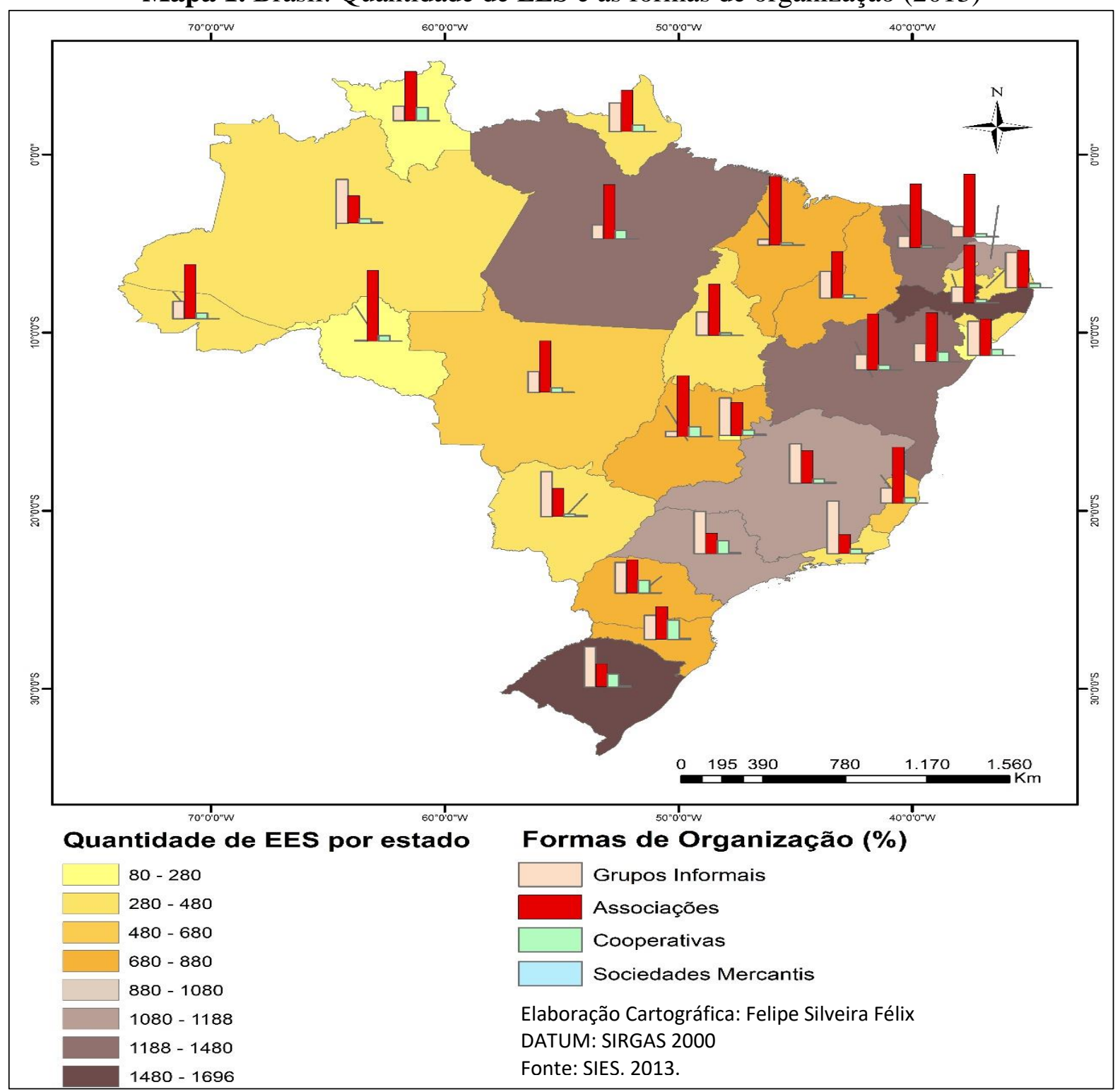

Fonte: SIES, 2013.

Para Locatel e Lima (2018), o cooperativismo brasileiro nunca teve, de fato, grande expressividade no que se refere ao fortalecimento da economia camponesa. Segundo os autores, o cooperativismo voltado à produção agrícola estruturou-se, a partir de 1932, com base na política pública de investimento e incentivo promovida pelo Estado por meio do Decreto 
22.239, de 19 de dezembro de 1932, que instituiu a Lei Básica do Cooperativismo Brasileiro. Esse movimento

[...] quase sempre se desenvolveu entre os grandes e médios produtores, ou seja, o segmento de latifundiários e de empresários rurais, mantendo os camponeses à margem desse movimento no campo ou, quando muito, inserindo-os como fornecedores de matéria-prima (LOCATEL; LIMA, 2018, p. 9).

Dado esse primeiro panorama dos empreendimentos solidários do país, traremos agora alguns dados de nível regional que auxiliam no entendimento da situação daqueles, no que se refere a PNES, bem como algumas tipologias que auxiliaram a análise do estado do Rio Grande do Norte.

O Gráfico 1 mostra a concentração de EES por região do país e o Gráfico 2 fornece-nos dados a respeito da área de atuação desses empreendimentos.

Gráfico 1. Brasil: Concentração dos EES (2013)

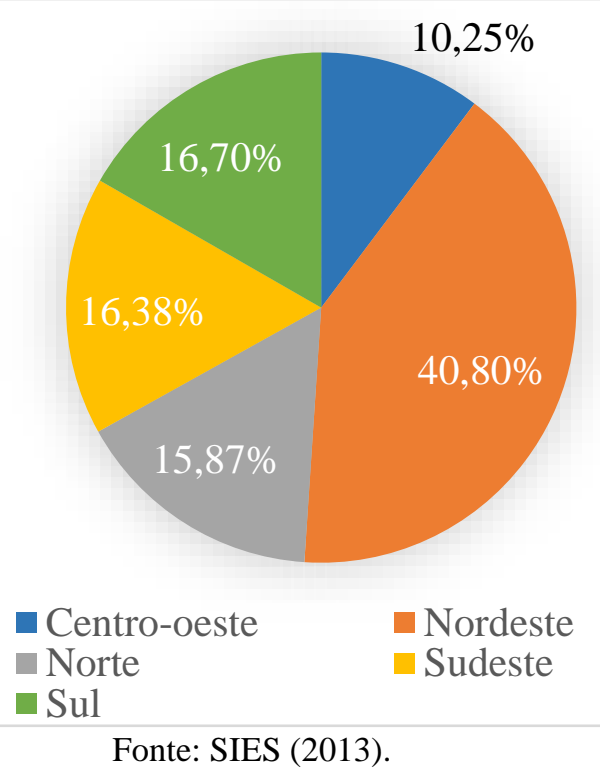

Gráfico 2. Brasil: Área de atuação dos EES (2013)

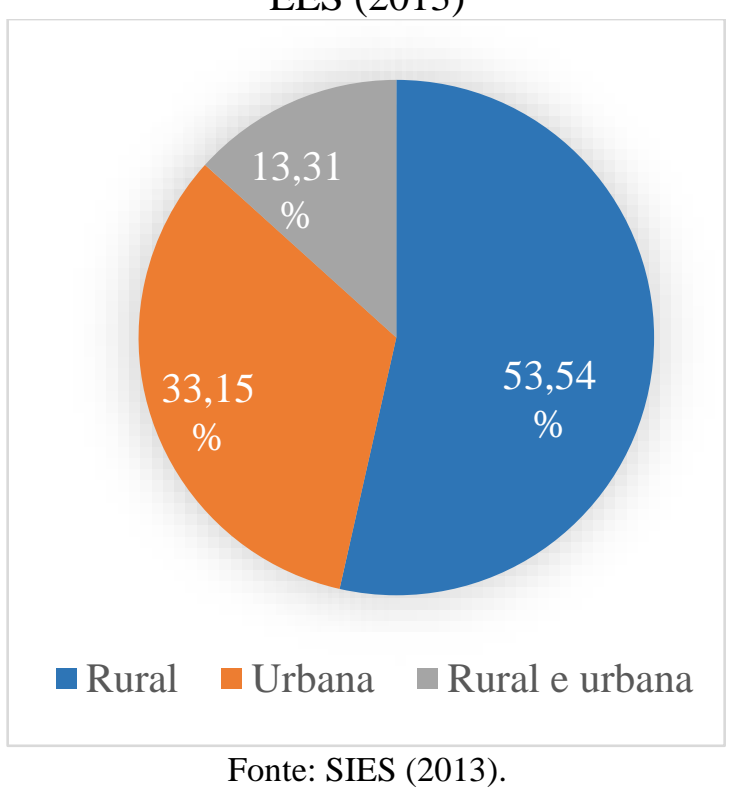

Como podemos ver no Gráfico 1, a região Nordeste concentra a maioria dos empreendimentos solidários do país. Essa expressiva concentração relaciona-se, principalmente, às desigualdades regionais no que concerne às infraestruturas - desde estradas até saneamento básico -, o que se soma à infraestrutura produtiva e à concentração fundiária, 
além da maior presença de população em situação de pobreza ${ }^{3}$ nas áreas rurais dos estados que compõem a região (IBGE, 2018) ${ }^{4}$, resultado do processo histórico de desenvolvimento desigual.

No Mapa 2, percebemos como se dá a distribuição espacial dos EES do país. Como dito anteriormente, há realmente uma concentração de empreendimentos no Nordeste, o que se pode verificar visualmente no mapa.

Mapa 2. Brasil: Número de Empreendimentos de Economia Solidária (2013)

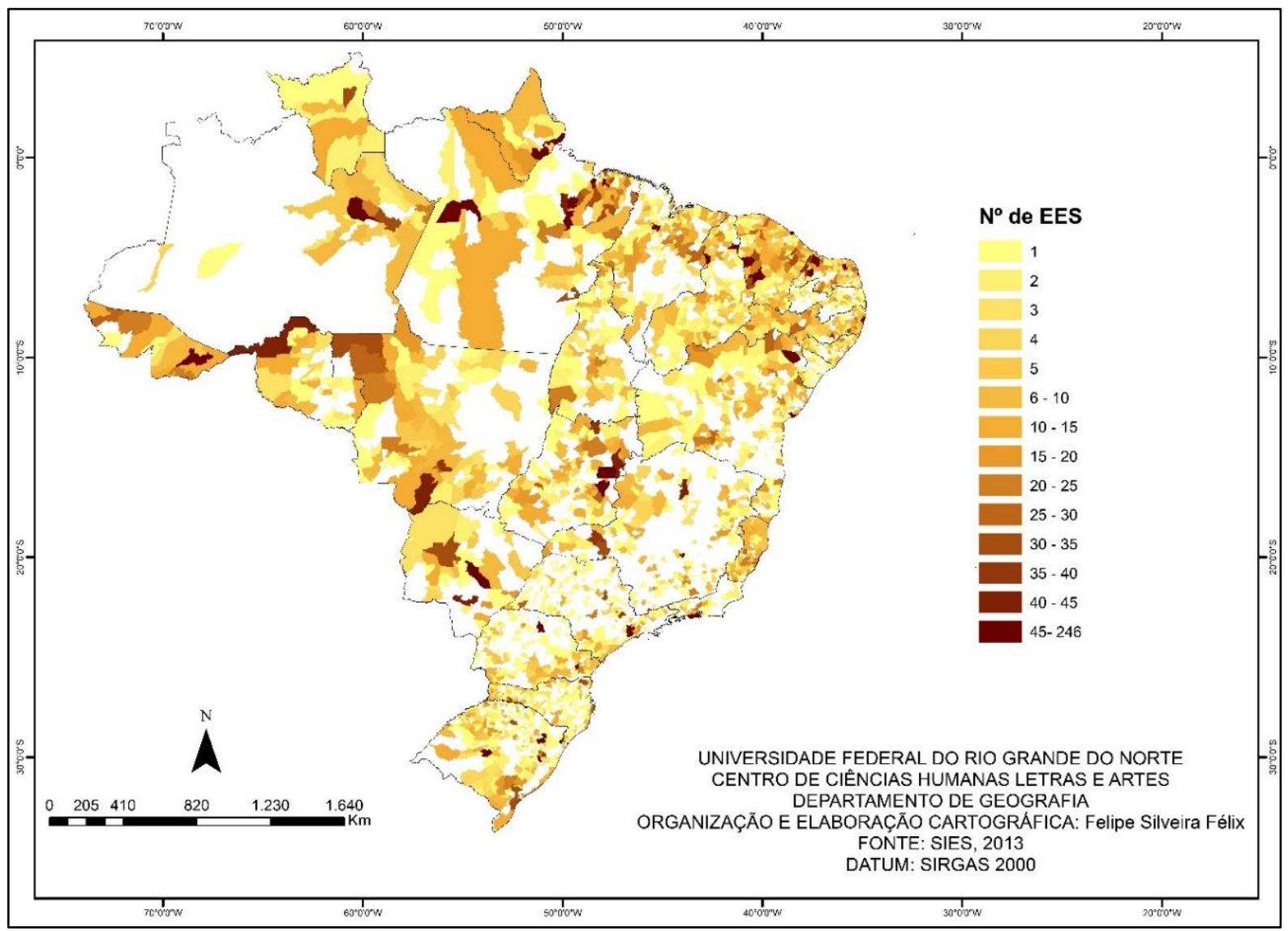

Fonte: SIES, 2013.

Nesse contexto, na região Nordeste, o estado do Rio Grande do Norte concentra 1158 EES, de um total de 8040 empreendimentos solidários, além de possuir o maior percentual de participantes da economia solidária em relação à população total do estado (Tabela 1).

\footnotetext{
${ }^{3}$ A definição de linha de pobreza foi proposta pelo Banco Mundial, o qual considera que o indivíduo que vive com rendimento de até US\$ 5,5 por dia se enquadra nessa situação.

${ }^{4}$ Ver Locatel (2012) e IBGE (2018).
} 
Tabela 1. Rio Grande do Norte: Representação dos participantes da economia solidária em relação ao número de população.

\begin{tabular}{c|c|c|c}
\multirow{2}{*}{ Variável } & \multirow{2}{*}{$N^{\circ}$ Total } & \multicolumn{2}{|c}{ Dados do Mapeamento no RN } \\
\cline { 3 - 4 } & & $N^{\circ}$ Total & Porcentagem \\
\hline População Total do RN & 3.373 .959 & 106.523 & $3,16 \%$ \\
\hline$N^{\text {o de Municípios }}$ & 167 & 132 & $79,04 \%$ \\
\hline \multicolumn{2}{|c}{ Fonte: IBGE (2013), SIES (2013). }
\end{tabular}

No caso do estado do Rio Grande do Norte, há a Lei 8.798, em vigor desde 2006, a qual instituiu a Política Estadual de Fomento à Economia Solidária e que possuía como diretriz principal “[...] a promoção da economia popular solidária e o desenvolvimento de grupos organizados e autogestionários de atividades econômicas, visando sua integração no mercado e a autosustentabilidade de suas atividades" (LEI N ${ }^{\circ} 8.798,2006, \operatorname{art.~}^{\circ}$ ).

Além do grande número de trabalhadores(as) associados(as) a empreendimentos solidários no RN, percebemos que os EES estão em mais de $79 \%$ dos municípios do estado. A partir do mapeamento do SIES (2013), verificou-se que, para a grande maioria dos empreendimentos, os motivos de sua criação foram: uma alternativa ao desemprego $(35,84 \%)$; a obtenção de maiores ganhos em um empreendimento associativo (35,32\%); o desenvolvimento comunitário de capacidades e potencialidades (34,72\%); uma fonte complementar de renda para os sócios $(30,40 \%)$.

Esse conjunto de variáveis relaciona-se às precárias condições de trabalho presentes no território potiguar, uma vez que a atuação do estado contribui mais para expropriar/explorar os pequenos agricultores do que para inserir os vetores da emancipação, da autonomia e da liberdade. Entretanto, os EES do RN obtiveram conquistas para a comunidade local em 51,12\% dos empreendimentos, bem como a geração de renda $(42,14 \%)$ e a integração do grupo/coletivo (40,59\%). Ainda assim, esses mesmos indicadores surgem enquanto desafios para os grupos do estado, uma vez que, para 59,33\%, viabilizar o empreendimento economicamente é um desafio que se alia a gerar renda adequada para os sócios $(53,11 \%)$ e a manter a união do grupo/coletivo $(32,47 \%)$, de acordo com o SIES (2013).

Há, no estado, uma dura realidade para os empreendimentos, pois, para a reprodução e o fortalecimento da economia solidária e desses EES, é necessário acesso a crédito e a financiamentos. Porém, como pode ser observado no Gráfico 3, 72\% não buscou crédito ou financiamento, enquanto $16 \%$ buscou sem obter êxito. Por outro lado, cerca de $70 \%$ dos empreendimentos do Rio Grande do Norte necessitam de financiamento para ampliação, aquisição de insumos, assessoria, construção de infraestruturas e investimentos no geral. Isso 
faz com que a falta de crédito e/ou de financiamento constitua uma dificuldade para os empreendimentos (SIES, 2013).

Gráfico 3. Rio Grande do Norte: Acesso a crédito pelos EES (2013)
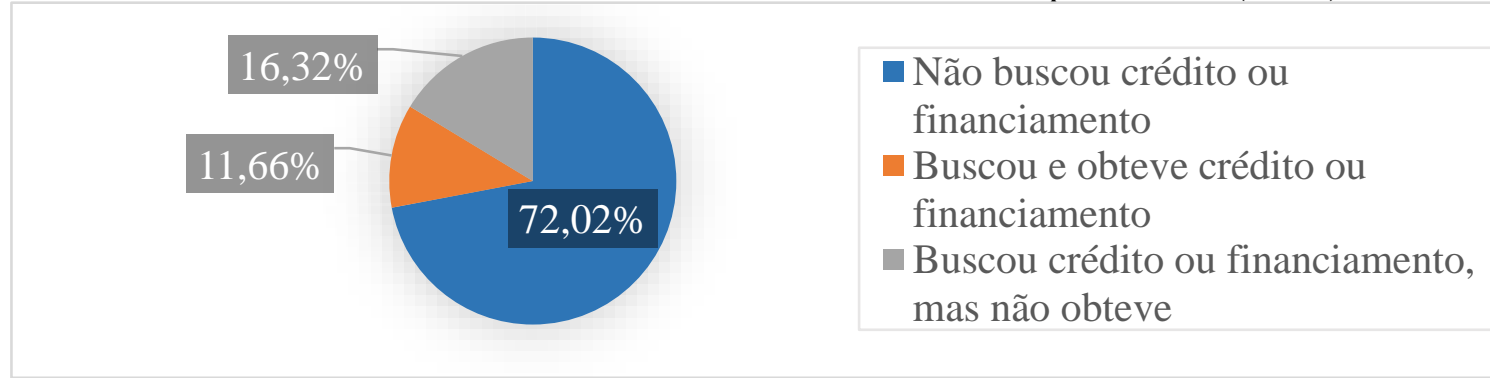

Fonte: SIES (2013).

Essas dificuldades se dão a partir de um conjunto de fatores, mas um dos principais é a pontual e fraca atuação do estado na operacionalização da política pública em Economia Solidária. No quadro 1, estão representados os valores das dotações iniciais e os valores destinados à operacionalização do PESD.

Quadro 1. Brasil: Dotação orçamentária para o Programa Economia Solidária em Desenvolvimento de 2003 a 2017.

\begin{tabular}{|c|c|c|c|c|c|c|}
\hline Órgão & \multicolumn{3}{|c|}{ Dotação Inicial (R\$) } & \multicolumn{3}{|c|}{ Valor Pago (R\$) } \\
\hline Ano & MTE & MDS & Total & MTE & MDS & Total \\
\hline 2003 & 0 & 0 & 0 & 0 & 0 & 0 \\
\hline 2004 & 29.110 .458 & 29.286 .298 & 58.396 .656 & 16.389 .844 & 5.112 .060 & 21.501 .905 \\
\hline 2005 & 13.220 .400 & 44.177 .606 & 44.177 .606 & 44.177 .606 & 44.177 .606 & 44.177 .606 \\
\hline 2006 & 12.870 .644 & 20.666 .530 & 33.533 .174 & 13.333 .630 & 0 & 13.333 .630 \\
\hline 2007 & 33.956 .600 & 27.545 .000 & 61.501 .000 & 17.175 .524 & 0 & 17.175 .524 \\
\hline 2008 & 49.023 .000 & 41.060 .000 & 90.083 .000 & 13.485 .987 & 10.409 .994 & 23.895 .981 \\
\hline 2009 & 34.684 .560 & 50.885 .000 & 85.569 .560 & 113.538 & 9.564 .079 & 9.677 .617 \\
\hline 2010 & 45.070 .000 & 63.884 .000 & 108.954 .000 & 8.654 .976 & 746.670 & 9.401 .646 \\
\hline 2011 & 65.584 .703 & 41.501 .264 & 107.085 .967 & 9.493 .641 & 15.986 .155 & 25.479 .796 \\
\hline 2012 & 0 & 0 & 0 & 6.759 .285 & 10.886 .623 & 17.465 .908 \\
\hline 2013 & 0 & 0 & 0 & 1.029 .149 & 800.000 & 1.829 .149 \\
\hline 2014 & 133.763 .798 & 50.736 .076 & 184.499 .874 & 1.499 .874 & 0 & 1.499 .874 \\
\hline 2015 & 52.888 .175 & 13.935 .667 & 66.823 .842 & 1.375 .904 & 0 & 1.375 .904 \\
\hline 2016 & 47.877 .418 & 6.078 .782 & 53.956 .200 & 0 & 0 & 0 \\
\hline 2017 & 34.459 .535 & 7.541 .351 & 42.000 .886 & 0 & 0 & 0 \\
\hline
\end{tabular}

Fonte: LOCATEL; LIMA, 2018.

Como observado no quadro, as dotações iniciais nunca corresponderam, de fato, aos valores pagos. Esses dificultam a operacionalização da Política Nacional de Economia Solidária 
(PNES) e do PESD, uma vez que, visto a grande quantidade de EES no país e a extensão do território nacional, os desdobramentos se dão no território de maneira desigual e, no caso do programa, há grande falta de subsídio para acesso ao crédito e aos financiamentos, para aquisição de recursos técnicos, para contratação de recursos humanos, para ajuda na assistência técnica e para os diversos investimentos necessários para a reprodução dos empreendimentos solidários do país. De acordo com Lima (2015), isso inviabiliza o desenvolvimento desses grupos, visto os ínfimos valores destinados à operacionalização dessa política.

Dessa forma, percebemos a dura realidade dos empreendimentos solidários do país, bem como do Rio Grande do Norte, em especial a partir de 2016, com o fim do Governo do Partido dos Trabalhadores e com o impeachment da Presidente Dilma Rousseff. Pode-se observar, no quadro 1, que, nos anos de 2016 e 2017, houve previsão orçamentária, mas que não houve aplicação dos recursos. Já a partir de 2018, não houve nem previsão orçamentária para o PESD.

Feita uma caracterização geral da distribuição do EES pelo país e de alguns aspectos da Política voltada para essas iniciativas, buscaremos entender como se dá o círculo de cooperação solidária formado a partir da atuação dos empreendimentos solidários e, por fim, buscaremos entender como se insere, nesse contexto, a Rede Xique-Xique de Comercialização Solidária.

\section{ECONOMIA SOLIDÁRIA E OS CÍRCULOS DE COOPERAÇÃO}

A economia solidária compreende, de acordo com Singer (2001), os diferentes tipos de “empresas" com distintas formas de organização, mas que convergem para um ponto em comum: o fortalecimento dos(as) trabalhadores(as) associados(as) e a mitigação das dificuldades vivenciadas em empreendimentos solidários, adversidades essas que o sistema dominante se nega a resolver.

Para entendermos a realidade e a atuação dos empreendimentos solidários do país, fazse necessário utilizarmos o conceito de território, visto que ele surge enquanto ferramenta de análise que faz "[...] emergir toda a concretude que a sociedade, na sua história, produz" (CATAIA, 2001, p. 6). Entretanto, Santos (2006) discorre que o conceito de território, em si, é uma abstração e que necessitamos de outros recursos para a análise espacial. Sendo assim, utilizamos do conceito de "território usado" (SANTOS, 2005), uma vez que as sociedades, ao produzirem seus territórios, condicionam e são condicionadas pelo uso daquilo que inventaram.

Nesse sentido, diversos são os agentes envolvidos na economia solidária e, também, na política pública em Economia Solidária. Temos desde a atuação vertical do Estado à atuação 
horizontal dos movimentos ligados à economia solidária. Essas verticalidades presentes na atuação estatal horizontalizam-se no território, atingindo os lugares de forma diferente, havendo, nesse processo, a intensificação das desigualdades já existentes (FÉLIX, 2019).

De acordo com Santos (2002), ao contrário do que ocorre nas verticalidades, nas horizontalidades funcionam, num mesmo tempo, diversos relógios, realizando-se diversas temporalidades. Trata-se, segundo o autor "[...] de um espaço à vocação solidária, sustento de uma organização em segundo nível, enquanto sobre ele se exerce uma vontade permanente de desorganização, ao serviço dos atores hegemônicos” (SANTOS, 2002, p. 111).

Dessa forma, no período técnico-científico-informacional, intensificam-se as "mudanças solidárias", uma vez que a incorporação de nexos e de normas longínquos e indiferentes ao lugar, a partir das verticalidades, têm um "[..] efeito desintegrador das solidariedades locais vigentes, com a perda correlativa da capacidade de gestão da vida local" (SANTOS, 2006, p. 193).

Nesse contexto, as solidariedades orgânicas, mais ligadas ao lugar, tendo imbricadas em si demandas, costumes e elementos culturais e sociais das populações locais, acabam por ser, segundo Antas Jr. (2005, n.p.), desequilibradas pelas organizacionais “[...] fortemente vinculada às tecnologias mais avançadas capazes de integrar porções territoriais não-contíguas que abarcam todo o planeta". Além disso, a partir de localidades longínquas, frias e insensíveis às realidades locais, promovem o desequilíbrio e a consequente desintegração das formas de solidariedade orgânica.

É nesse sentido que o uso do território se dá a partir das grandes empresas. É um uso corporativo do território, com a produção de uma lógica territorial das grandes empresas, o que pode ser visto por meio da topologia da empresa, que seria, basicamente, a distribuição dos pontos de interesse para a operação dela (SANTOS; SILVEIRA, 2006). Dessa forma, o uso corporativo caracteriza-se como um uso do território enquanto recurso, uma vez que as lógicas das empresas têm pouca relação com o lugar e, além disso, ele torna-se de uso hierárquico também, visto que as corporações com maior poder econômico e político " [...] escolhem os pontos que consideram instrumentais para sua existência produtiva [...] O resto do território torna-se, então, o espaço deixado às empresas menos poderosas" (SANTOS; SILVEIRA, 2006, p. 294).

O uso do território para os empreendimentos solidários, nessa lógica, acaba se dando primeiro enquanto abrigo, mas também como recurso, uma vez que suas lógicas são ligadas ao lugar. Na perspectiva dos agentes sujeitados, reféns de lógicas cruéis e perversas do modelo 
hegemônico, o território se converte em abrigo, uma vez que suas lógicas são ligadas ao lugar, em oposição aos vetores da globalização e da atuação corporativa do capital, que busca regular o território utilizando-o enquanto recurso e explorando-o a fim de assegurar a reprodução ampliada do capital.

Um outro ponto a se discutir é o círculo de cooperação que se constitui a partir da atuação dessas grandes corporações, uma vez que este constitui-se justamente na busca pelo fortalecimento econômico, ligado à produção capitalista, tendo as práticas solidárias ou cooperativas gestadas e pautadas pelo modelo hegemônico. Para Santos e Silveira (2006), os fluxos não materiais ditam, em grande parte, o movimento no espaço. Nesse sentido, “[...] essa é a inteligência do capital, reunindo o que o processo direto da produção havia separado" (SANTOS; SILVEIRA, 2006, p. 144), isto é, ligando lugares e empresas através de círculos de cooperação que, juntamente com os Circuitos Espaciais da Produção, mostram como se dá o uso diferenciado de cada território por parte das grandes corporações, ligando, também, porções territoriais distantes que, em certos casos, extrapolam as fronteiras nacionais.

Os empreendimentos solidários seguem também uma lógica cooperativa, mas não a mesma dessas grandes empresas. De fato, buscam, na constituição de redes solidárias, o fortalecimento dos(as) trabalhadores(as), bem como a minimização das relações de subordinação destes ao capital. Nesse sentido, gesta-se um círculo de cooperação contrário a essa lógica hegemônica, logo, um círculo de cooperação contra-hegemônico. Este surge, segundo Lima (2015)

[...] como forma alternativa à racionalidade hegemônica, os quais buscam a organização econômica socializada, pois as etapas de produção, antes restritas a escala local, agora transcendem o lugar da produção e se ampliam pelo território para fortalecer o processo de comercialização e as etapas do trabalho, a fim de que a subordinação ao capital seja menor e a emancipação desses empreendimentos se dê de forma plena (LIMA, 2015, p. 82)

Os empreendimentos econômicos solidários vivem num constante esforço para que se torne possível uma economia popular, bem como o bom desenvolvimento dos grupos autogestionários. Há nos EES diferenças que os inserem num outro contexto de círculo de cooperação, uma vez que, diferente das grandes empresas e corporações, nas quais existem hierarquias e subordinação entre agentes, percebemos que, nos empreendimentos solidários, as ações e constituições de redes solidárias surgem enquanto resistência às ações hegemônicas, o que as inseria num Círculo de Cooperação Contra-hegemônico. 
Nesse contexto, a Rede Xique-Xique de Comercialização Solidária (RXX) insere-se como força contra-hegemônica que busca proporcionar aos(as) trabalhadores(as) subsumidos ao processo de exclusão e de desigualdade uma nova realidade social e econômica. Assim, a RXX surge, nesse sentido, enquanto alternativa à organização dos(as) trabalhadores(as) do estado do Rio Grande do Norte. Dito isso, na próxima sessão, discutiremos a Rede, sua materialidade e o uso do território a partir de sua atuação.

\section{A REDE XIQUE-XIQUE: PRINCÍPIOS E MATERIALIDADE}

Neste momento, entraremos na discussão mais específica do nosso objeto de análise, o qual se constitui enquanto o foco deste trabalho: a Rede Xique-Xique de Comercialização Solidária.

A RXX é formada por trabalhadores(as) da agricultura familiar, do artesanato e, também, pelos consumidores. Tem por objetivo a produção, a comercialização e o fomento à articulação em rede na perspectiva da economia solidária, do feminismo e da agroecologia através do comércio justo e da certificação participativa (XIQUE-XIQUE, 2019). A Rede abrange cerca de 15 municípios no estado do Rio Grande do Norte, sendo estes: Apodi, Baraúna, Felipe Guerra, Grossos, Governador Dix-Sept Rosado, Janduís, Messias Targino, Mossoró, Natal, Parnamirim, Pendências, São Miguel, São Miguel do Gostoso, Tibau e Upanema. Cada município caracteriza-se como núcleo da Rede, sendo considerado ponto de gestão e, também, de comercialização a partir das feiras locais (XIQUE-XIQUE, 2019).

A criação da Rede, em si, segundo os gestores, ocorreu no ano de 2004, quando perceberam que, para fortalecer outros produtores da região do Alto Oeste Potiguar, era necessário não só o espaço de comercialização que eles possuíam na cidade de Mossoró (RN) (sede da rede), mas uma rede de organização entre os(as) trabalhadores(as) de outros municípios. Foi a partir da organização de entidades e de pessoas, do grupo de mulheres e das cooperativas e associações que a Rede Xique-Xique foi estabelecida no ano de 2004.

Estima-se que congregue, diretamente, cerca de 400 associados(as) e que, indiretamente, o número chegue a mais de 1000. De acordo com Lima (2015), a RXX caracteriza-se como o mais bem estruturado empreendimento econômico solidário do RN, possuindo grande diversidade de produtos, além de estar bastante alinhada com as práticas solidárias. Isso ocorre justamente porque a Xique-Xique tem sua carta de princípios baseada na economia solidária, no feminismo e na agroecologia. E é com base nisso que busca 
trabalhadores(as) para associarem-se à Rede, uma vez que eles(as) ou os grupos de trabalhadores(as) devem seguir esses princípios para associarem-se a RXX.

A Rede Xique-Xique de Comercialização Solidária surge a partir de uma lógica solidária e, além disso, estando alinhada a diversos movimentos sociais que vivenciam o território, primeiramente, enquanto abrigo. Desse modo, a RXX surge a partir da atuação horizontal - de base popular/social -, por meio da atuação desses movimentos sociais ligados ao campo, ao feminismo, à agroecologia e à economia solidária. Dessa maneira, atende às demandas dos agentes que resistem às lógicas hegemônicas, inserindo-se num círculo de cooperação contra-hegemônico e possibilitando uma nova experiência econômica, além de mudanças de caráter social para seus(suas) associados(as).

Para uma melhor análise da materialidade da Rede Xique-Xique, faz-se necessária a análise de algumas tipologias presentes no mapeamento nacional que nos darão os subsídios para entender como se caracteriza essa Rede no território potiguar.

Com relação aos motivos de criação, a gestora da RXX, Francisca Eliane, elencou estes como principais motivos:

- produção e/ou comercialização de produtos orgânicos ou ecológicos;

- alternativa organizativa e de qualificação;

- desenvolvimento comunitário de capacidades e potencialidades;

- desenvolvimento de uma atividade em que todos(as) são donos(as);

- uma fonte complementar de renda para os(as) associados(as);

- obtenção de maiores ganhos em um empreendimento associativo.

Esses indicadores vão ao encontro dos princípios da RXX, já que ela é pautada a partir de uma base social, agroecológica e que busca emancipar, fortalecer e dar autonomia aos(as) trabalhadores(as).

Além dos motivos de criação, é imprescindível entender como as questões ligadas ao acesso a crédito e à necessidade de financiamento se dão no empreendimento. No caso, de acordo com a gestora, há, sim, necessidade de financiamento por parte do empreendimento, de modo que a Xique-Xique buscou crédito, mas não o obteve, assim como não obteve financiamentos. Essa realidade dificulta a atuação da Rede e não fomenta o crescimento nem a reprodução social dos(as) trabalhadores(as). Essa realidade adversa intensifica-se ainda mais, como se percebe quando a gestora informa que a Xique-Xique, além de não ter conseguido financiamento e crédito no ano de 2019, teve resultados financeiros que deram apenas para 
pagar as despesas, sem haver nenhuma sobra. Isso inviabiliza, em grande medida, a aquisição de equipamentos e de insumos e o investimento em infraestruturas, além de outros investimentos.

Entretanto, mesmo diante dessa realidade difícil, a Rede Xique-Xique investiu, no ano de 2019, em: comunicação/divulgação; capacitação de mão de obra; equipamentos (aquisição, renovação); infraestrutura física (prédios, construções etc.).

Esses investimentos foram possíveis graças ao trabalho dos(as) associados(as), bem como devido às parcerias com outros movimentos e grupos. Desse modo, demonstra-se aqui que a Xique-Xique busca as conexões e as ligações para que, mesmo sem o acesso a crédito oriundo do estado ou do Governo Federal, a Rede consiga se reproduzir e garantir a reprodução social dos(as) associados(as).

Mesmo vivenciando uma realidade adversa, a Rede e os(as) associados(as) tiveram como principais conquistas a integração do grupo/coletivo e, também, a autogestão e o exercício da democracia. Entretanto algumas dificuldades se fazem presentes e, mesmo com essas conquistas, alcançar a conscientização e a politização dos(as) associados(as) ainda é um desafio para o empreendimento, assim como garantir a proteção social para os(as) sócios(as). Apesar disso, a Rede busca alternativas para a mitigação dessas dificuldades a partir das parcerias com outros movimentos, bem como a partir da Cooperativa de Comercialização Solidária XiqueXique (COOPERXIQUE).

Além dos(as) trabalhadores(as) associados(as), a RXX possui cerca de 61 cooperados na COOPERXIQUE, que são os(as) produtores(as) que possuem maior volume de produção, chegando, em alguns casos, a ter quantidade maior do que o montante comercializado na feira de seu núcleo/município. Esses(as) trabalhadores(as) enviam suas produções até o município de Mossoró/RN, onde é feita a comercialização não só nas feiras e na loja física, como também a partir do acesso aos mercados institucionais.

No Quadro 2, estão representados os dados disponibilizados pela COOPERXIQUE. Nele encontram-se algumas informações que corroboram nosso entendimento em relação à Xique-Xique, mostrando que ela se constitui, de fato, como rede bem estruturada, congregando diversos(as) trabalhadores(as) numa perspectiva solidária e cooperativa. 
Quadro 2. COOPERXIQUE: Síntese das informações da cooperativa.

\begin{tabular}{|c|c|c|c|c|}
\hline Principais produtos & $\begin{array}{c}\text { Mercados } \\
\text { acessados }\end{array}$ & $\begin{array}{c}\mathrm{N}^{\mathrm{o}} \text { de } \\
\text { Cooperados }\end{array}$ & $\begin{array}{c}\text { Faturamento } \\
-2018\end{array}$ & Desafios e dificuldades \\
\hline Hortifrutigranjeiros, \\
$\begin{array}{c}\text { Castanha, Arroz } \\
\text { vermelho, Mel e } \\
\text { derivados }\end{array}$ & $\begin{array}{c}\text { PAA, } \\
\text { PNAE e } \\
\text { Feiras } \\
\text { Municipais } \\
\text { e Estaduais }\end{array}$ & 61 & $\begin{array}{c}\text { Ganhos: } \\
116.396,85\end{array}$ & $\begin{array}{c}\text { Logística e Agroindústria } \\
\text { certificada }\end{array}$ \\
\cline { 3 - 5 } & & $\begin{array}{c}\text { Perdas: } \\
10.471,11\end{array}$ & $\begin{array}{c}\text { Transporte e } \\
\text { beneficiamento(rotulagem, } \\
\text { valoricional e código } \\
\text { de barras) }\end{array}$ \\
\hline
\end{tabular}

Fonte: COOPERXIQUE, 2019.

A atuação da Rede Xique-Xique é forte justamente porque a atuação dos(as) trabalhadores(as) também o é. Como observamos, a diversidade de mercados acessados dá aos(as) associados(as) condições reais de comercialização de suas produções. Além disso, há grande variedade de produtos comercializados (quadro 3), os quais são produzidos a partir de matrizes agroecológicas e/ou orgânicas.

Quadro 3. COOPERXIQUE: produtos produzidos e comercializados pela Rede Xique-Xique e pela cooperativa.

\begin{tabular}{|c|c|}
\hline Núcleo & Produção \\
\hline Verduras & $\begin{array}{l}\text { Alface (Americano, roxo, crespo); Coentro; } \\
\text { Cebolinha; Chicória; Almeirão; Espinafre; Acelga. }\end{array}$ \\
\hline Frios & $\begin{array}{l}\text { Galinha; Guiné; Carne de Bode e Carneiro; Queijo } \\
\text { Coalho; Queijo Manteiga; Polpa de frutas; Doce de } \\
\text { leite; Extrato de tomate. }\end{array}$ \\
\hline Legumes & $\begin{array}{l}\text { Maxixe; Beterraba; Tomate cereja; Tomate de mesa; } \\
\text { Urucum; Pimenta (de bico; de cheiro; macaco); } \\
\text { Quiabo; Cebola. }\end{array}$ \\
\hline Frutas & $\begin{array}{l}\text { Acerola; Manga; Goiaba; Pinha; Tamarindo; } \\
\text { Graviola; Ciriguela; Cajarana; Banana; Caju; } \\
\text { Maracuiá. }\end{array}$ \\
\hline Mel e Derivados & $\begin{array}{l}\text { Pólen desidratado; Extrato de própolis; Pomada de } \\
\text { própolis; Mel; Favo de Mel; Mel em sachê. }\end{array}$ \\
\hline Diversos & $\begin{array}{l}\text { Ovo caipira; Pão de leite de cabra; Pão integral; } \\
\text { Geleia; Xarope; Óleo de coco; Coco in natura; Bolo; } \\
\text { Biscoito; Algas. }\end{array}$ \\
\hline Artesanato & $\begin{array}{l}\text { Bolsa de ombro; Bolsa de costas; Bonecas; Arte em } \\
\text { Biscuit; Porta celular; Porta joia; Porta retrato. }\end{array}$ \\
\hline
\end{tabular}

Fonte: COOPERXIQUE, 2019.

Percebemos, a partir da observação do quadro 3, que há uma grande variedade de produtos comercializados nos núcleos, alguns dificilmente encontrados em mercados e em 
supermercados convencionais. Quando aí são achados, custam preços exorbitantes e, na maioria dos casos, foram obtidos justamente de pequenos produtores rurais que, por não terem a possibilidade de comercialização ou um local para isso, passaram suas produções para atravessadores a preços baixíssimos. Essa realidade é confrontada pela RXX, uma vez que os(as) associados(as) têm outras formas e locais para a destinação de suas produções, o que os fortalece e dá-lhes subsídios para a mitigação da sujeição destes aos atravessadores.

Nesse sentido, é na mitigação dessas dificuldades que a Rede busca, nas parcerias com entidades de assessoria, de financiamento e de crédito, além de outras redes solidárias, fóruns e ONGs, mitigar essas dificuldades. A articulação em rede e os elos e conexões estabelecidos pela RXX possibilitam sua continuação e o fortalecimento da economia solidária potiguar. No Mapa 3 podemos observar como a RXX está especializada no estado do RN, a concentração de cooperativas e de associações e a quantidade de EES por município.

Mapa 3. Rio Grande do Norte: Quantidade de EES por município e Formas de Organização nos municípios da Rede Xique-Xique (2013)

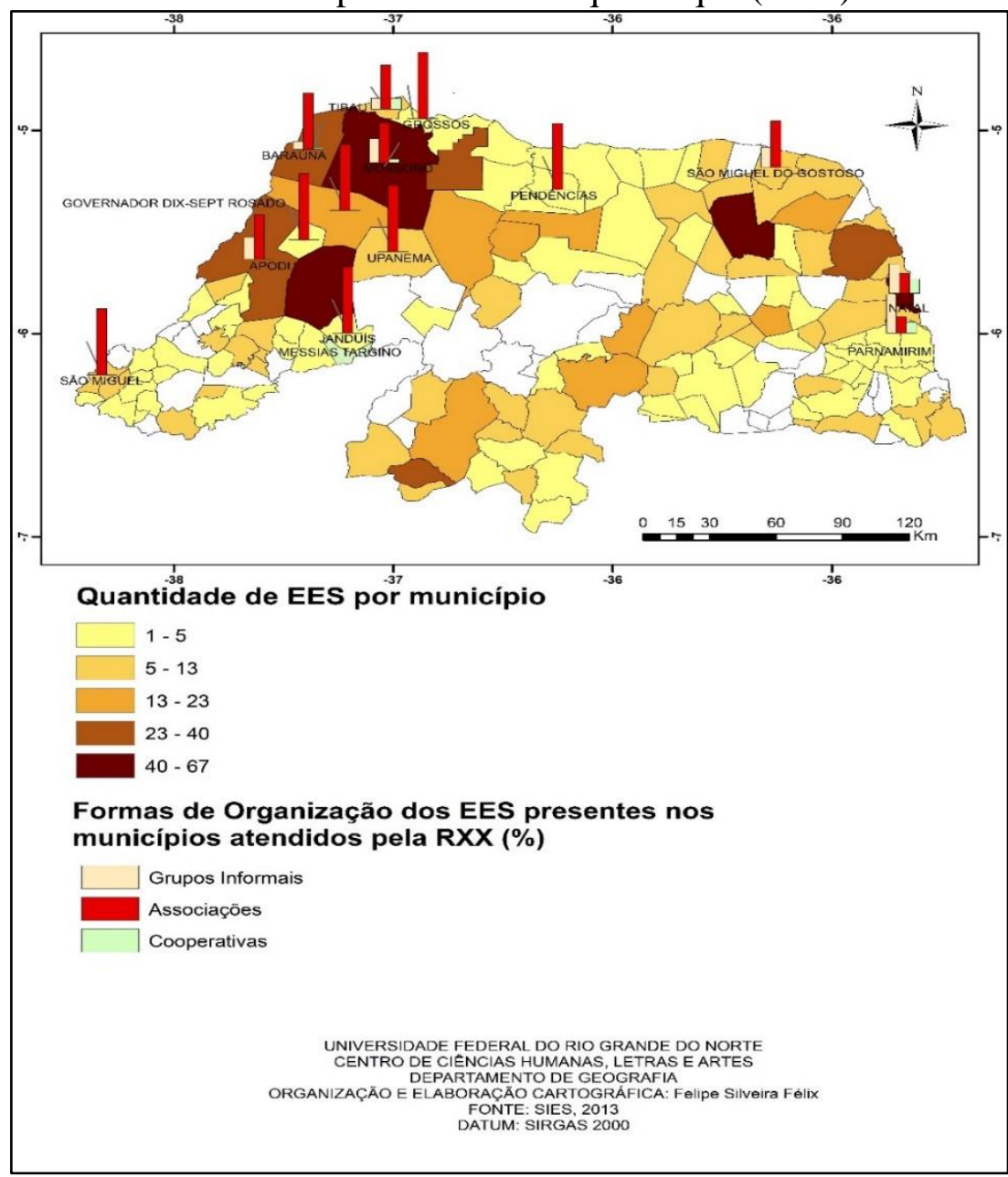

Fonte: SIES, 2013; XIQUE-XIQUE, 2019. 
Como podemos observar no Mapa 3, há uma grande maioria de empreendimentos organizados em forma de associação, seguidos de grupos informais. Percebe-se, também, que a RXX está presente não apenas em municípios com grande número de EES, mas, em alguns casos, em municípios que possuem de 1 a 5 empreendimentos. Isso ocorre devido os processos de sensibilização e de trabalho de base que a Rede promove nos municípios ondem existem grupos ou produtores com interesse de associarem-se à Xique-Xique, mostrando que não há um interesse estritamente econômico na expansão da Rede no estado.

Pensando num viés economicista, a RXX se instalaria apenas em municípios com muitos empreendimentos, visto que, com isso, poderia conseguir, nesses municípios, um número maior de possíveis associados, o que traria benefícios econômicos para a Rede. Porém, como percebemos, essa não é a realidade, pois a Xique-Xique atende às demandas de grupos e de trabalhadores(as) que veem a atuação da Rede e que se interessam por dela fazerem parte. Mas, para isso, é necessário que os grupos e/ou trabalhadores(as) sigam os princípios da RXX, trabalhando na perspectiva do feminismo, da agroecologia e da economia solidária.

Alguns pontos se tornam interessantes na análise da topologia territorial da Rede XiqueXique. Percebe-se que a forma de organização dos empreendimentos ou dos grupos, que o engajamento com movimentos sociais e que a participação de fóruns e de redes de articulação são elementos que podem explicar, em parte, a topologia da RXX. De fato, analisar essa questão é tarefa difícil, uma vez que a realidade é muito complexa, pois existem diversos outros elementos que levam à decisão de instalação da Rede nos municípios. Entretanto o que se pode afirmar aqui é que, de fato, a Xique-Xique alinha-se fortemente com a economia solidária e com a busca, a partir disso, por superar as barreiras impostas pelo modelo hegemônico a partir de ações de resistência, de ações contra-hegemônicas.

O que percebemos é que há, como observa-se no Mapa 3, desigual e concentrada distribuição de empreendimentos no estado, o que, de acordo com Lima (2015), reflete o quanto a política de Economia Solidária ainda é insuficiente para atingir os objetivos pretendidos e fomentar, de fato, a Economia Solidária Potiguar, uma vez que a maioria dos empreendimentos não possui as condições básicas para que as experiências solidarias tenham o real potencial de transformação social. Nesse sentido, a Xique-Xique atua com o objetivo de fortalecer os(as) trabalhadores(as) e os empreendimentos associados frente às adversidades impostas pelos agentes hegemônicos. 


\section{CONSIDERAÇÕES FINAIS}

Nota-se que as políticas públicas voltadas para a economia solidária não geram, de fato, significativas mudanças para os empreendimentos. Diante disso, a PNES e a Política Estadual de Fomento à Economia Solidária devem aproximar-se mais das realidades locais, entendendo as peculiaridades do lugar, uma vez que é nele que se dá a concretude dos processos espaciais. Isso deve ser feito a fim de diminuir as contradições das ações adotadas pelo Estado.

Outro ponto interessante é a inexistência de políticas de Estado, uma vez que a PNES nada mais é que uma política de governo e, como vimos neste trabalho, o orçamento destinado para a operacionalização dela, na maioria dos anos, foi parco e ineficiente; da mesma forma, em outros anos, não foram destinados quaisquer valores para a continuação da política. Nesse sentido, o imediatismo presente no modelo político brasileiro é um dos principais problemas, visto que os governos que se dispuseram a atender às demandas do movimento da economia solidária o fizeram de forma rápida, mas sem uma estruturação completa, por meio de pastas/órgão estatais e de recursos próprios voltados para o atendimento dessas demandas. Isso fragilizou bastante a operacionalização da PNES, tanto que, a partir da ascensão do governo de extrema direta, desde 2017, não houve destinação de recursos para o Programa Economia Solidária em Desenvolvimento (PESD).

Percebe-se que há, de fato, um círculo de cooperação hegemônico, formado pelas grandes corporações e pelo Estado, assim como um círculo de cooperação contra-hegemônico que surge a partir da atuação de resistência dos empreendimentos solidários, especificamente, no caso analisado, da Rede Xique-Xique de Comercialização Solidária.

A RXX, no estado do Rio Grande do Norte, mostra-nos que é possível criar novas lógicas de fortalecimento, de emancipação e de autonomia dos(as) trabalhadores(as). Entretanto nem todas as dificuldades podem ser mitigadas apenas com a atuação da Rede, uma vez que a economia solidária se institucionalizou. Desse modo, mesmo com a normatização da economia solidária e com o fomento à criação de novos empreendimentos, ainda é necessário um ambiente institucional mais forte, com recursos e orçamentos e técnicos e profissionais que possam prestar assistência aos EES do país. No caso do Rio Grande do Norte, um ambiente institucional que também dê as condições de reprodução dos empreendimentos do estado.

A RXX, diante da lógica hegemônica que subjuga os(as) trabalhadores(as) e que os expropria e subordina-os, mostra-se como resistência a essa realidade. $\mathrm{O}$ círculo de cooperação formado a partir da atuação em rede, por parte da RXX, fortalece não só os(as) associados(as), 
como também a economia solidária potiguar. Sendo assim, a Xique-Xique segue num constante e contínuo processo de construção de um ambiente favorável ao bom desenvolvimento da economia solidária no estado, tendo como fim o alcance de um comércio justo e a geração de trabalho e renda a partir de lógicas solidárias e cooperativas.

Dito isso, percebemos, com este trabalho, que a criação de redes solidárias, como a Rede Xique-Xique - que preza pelas lógicas solidárias e, além disso, por toda uma base social, ligando-se ao feminismo e também à agroecologia -, leva a círculos de cooperação contrahegemônicos que fortalecem ainda mais a atuação dos EES. Entretanto, mesmo com o desenvolvimento gerado a partir da atuação em rede, os empreendimentos solidários ainda encontram na atuação do Estado, com as regulações e normatizações vigentes, elementos que acabam por precarizar as condições de desenvolvimento, em especial por serem medidas estatais que visam tutelar os empreendimentos solidários ao invés de estimular a emancipação numa lógica contrária à do mercado. Isso se demonstra por meio das ações realizadas pelo Estado brasileiro, entre 2013 e 2016, as quais se voltaram a estimular a inserção dos(as) trabalhadores(as) no mercado capitalista.

Por fim, entendemos que há uma complexidade de interrelações que se estabelecem entre os distintos agentes envolvidos na economia solidária e que, nesse sentido, não se esgotam aqui as possibilidades de análise desta, bem como em relação à Rede Xique-Xique de Comercialização Solidária. A RXX demonstra-se, enquanto objeto a ser analisado, a partir de diversas perspectivas e é fato que tem fundamental importância para a dinâmica da economia solidária potiguar. Nesse sentido, é imprescindível que haja uma relação mais intrínseca entre as políticas públicas de economia solidária e o lugar. Desse modo, necessita-se que a atuação estatal seja guiada pelos anseios da população e que, além disso, seja pensada de modo que a política incida no território de maneira vertical, mas que não rompa antigas solidariedades orgânicas para que, assim, seja possível horizontalizar-se no território de forma não tão concentrada e desigual, como no caso da PNES. Da mesma forma, é preciso que tal atuação não fique em segundo plano, sendo pensada a partir de um caráter estritamente econômico, uma vez que a economia solidária compreende não só as formas de organização dos(as) trabalhadores(as), mas também de todo um conjunto de lógicas ligadas, principalmente de âmbito social. 


\section{REFERÊNCIAS}

ANTAS JUNIOR, Ricardo Mendes. Território e Regulação: espaço geográfico, fonte material e não-formal do direito. São Paulo: Humanitas, 2005. 248 p.

AZEVEDO, Francisco Fransualdo de; SILVA, Rafael Pereira da; ALIÓ, Maria Angels. Outra maneira de controle do espaço: o poder das economias sociais e solidárias no território brasileiro. In: Anais do XIII Coloquio Internacional de Geocrítica. Barcelona, 2014. Disponível em: http://www.ub.edu/geocrit/coloquio2014/Francisco Fransualdo de Azevedo.pdf. Acesso em: 30 set. 2019.

CATAIA, Márcio A. Território nacional e fronteiras internas: a fragmentação do território brasileiro. 2001, 164f. Tese (Doutorado em Geografia). Faculdade de Filosofia, Letras e Ciências Humanas, Universidade de São Paulo, São Paulo, 2001.

FORBELONI, J. V. Políticas públicas e economia solidária: alternativas de geração de trabalho e renda no estado do Rio Grande do Norte. In: XI Congresso Luso-Afro-Brasileiro de Ciências Sociais. Salvador: Universidade Federal da Bahia - UFBA, 2011.

IBGE. Síntese de Indicadores Sociais: indicadores apontam aumento da pobreza entre 2016 e 2017. Disponível em: <https://agenciadenoticias.ibge.gov.br/agencia-sala-deimprensa/2013-agencia-de-noticias/releases/23298-sintese-de-indicadores-sociaisindicadores-apontam-aumento-da-pobreza-entre-2016-e-2017>. Acesso em: 10 de fev. 2020.

LIMA, Leandro de Castro. Os usos do território e a economia solidária no Rio Grande do Norte. 2015. 245f. Dissertação (Mestrado em Geografia) - Centro de Ciências Humanas, Letras e Artes, Universidade Federal do Rio Grande do Norte, Natal, 2015.

LOCATEL, Celso Donizete; LIMA, Leandro de Castro. Do cooperativismo à economia solidária: normatização e dinâmica econômica no campo brasileiro. In: XV Coloquio Internacional de Geocrítica. Barcelona: Universidad de Barcelona, 2018. Disponível em: <http://www.ub.edu/geocrit/XV-Coloquio/LocatelLima.pdf>. Acesso em: 17 mai. 2019.

LOCATEL, Celso. Tecnificação dos territórios rurais no Brasil: políticas públicas e pobreza. Scripta Nova. Revista Electrónica de Geografía y Ciencias Sociales. Barcelona: Universidad de Barcelona, 1 de noviembre de 2012, vol. XVI, nº 418 (66). Disponível em: <http://www.ub.es/geocrit/sn/sn-418/sn-418-66.htm>. Acesso em: 10 de fev. 2020.

PIRES, Aline Suelen; ROSSI, Renan. Cooperativismo Católico: uma feição cristã da economia solidária no Brasil. Áskesis, v. 6, n. 1, p. 88, 2017. Disponível em: < http://www.revistaaskesis.ufscar.br/index.php/askesis/article/view/193>. Acesso em: 05 dez. 2019.

SANTOS, Milton. A Natureza do Espaço: Técnica e Tempo, Razão e Emoção. 4. ed. São Paulo: Edusp, 2006.

SANTOS, Milton. Por uma outra globalização: do pensamento único à consciência universal. 9. ed. Rio de Janeiro: Record, 2002. 
SANTOS, Milton et al. Territorio y movimientos sociales. OSAL: Observatorio Social de America Latina, v. 6, n. 16, p. 251-261, 2005.

SANTOS, Milton; SILVEIRA, María Laura. O Brasil: território e sociedade no início do século XXI. 9. ed. Rio de Janeiro: Record, 2006.

SILVA, Sandro Pereira; NAGEM, Fernanda A. A economia solidária na Agenda das Políticas Públicas Nacionais: uma análise do Programa Economia Solidária em Desenvolvimento.

Texto para Discussão, v. 1682. Brasília: IPEA, 2011. Disponível em:

$<$ http://www.ipea.gov.br/portal/index.php?option=com_content\&view=article\&id=15154>. Acesso em: 08 jan. 2020.

SINGER, Paul. Economia solidária versus economia capitalista. Sociedade e Estado, v. 16, n. 1-2, p. 100-112, Brasília, 2001. Disponível em < http://www.scielo.br/pdf/se/v16n12/v16n1-2a05.pdf>. Acesso em: 08 jan. 2020. http://dx.doi.org/10.1590/S010269922001000100005 .

Recebido em 22 de agosto de 2021

Aprovado em 18 de novembro de 2021

Publicado em 07 de fevereiro de 2022. 